\title{
Suicide as a social dilemma: Evidence from Pakistan
}

\author{
Zubair Ahmed \\ Karakoram International University \\ Giligit Baltistan \\ Ilyas Bhati \\ Assistant Professor in the Department of Anthropology \\ Quaid-i-Azam University Islamabad \\ Rizwana Kausar \\ Department of Sociology \\ Allama Iqbal Open University Islamabad
}

\begin{abstract}
Suicide is one of the major causes of death around the globe. It has become sensitive and imperative anthropological, psychological and public health issue which need to be tackled. The present paper provides an overview of the growing literature on suicide or more commonly known as "attempted suicide or completed suicide". Suicidal attempts (and /or completed suicides) are increasing in urban and rural areas of Pakistan such as Karachi, Ghizer, and Hunza. The exact reasons are indefinite. This paper focuses on existing literature 1) the concept of suicide; 2 ) analyzes the existing consensus/figures of suicide in Pakistan; 3) analyzes the main determinants; 4) risk factors of suicide; 5) analyzes the modes of suicide discussed in the existing literature on suicides in Pakistan; and 6) offers literature gap and limitations of the evidences. It has revealed that the exact factors of socio-cultural and economical determinants of suicide in rural and urban areas were investigated paradoxically due to lack of meticulous quantitative and qualitative research. Majority studies focused on suicide in women but not even a single study focused on underlying factors of suicide in men. Further methodical studies are suggested at the community level.
\end{abstract}

Keywords: evidence, Pakistan, social dilemma, suicide, women

\section{INTRODUCTION}

Suicide is one of the major causes of death around the globe. It is an understudied matter and under-researched subject in Pakistan. Suicide can be understood as a kind of sociality and social relationship through which people create meaning in their lives. Suicide, generally accepted, is ultimately a deadly violence directed against self. As a form of death it has evoked and evokes a multiplicity of reactions from the living, ranging from sadness and fascination to repulsion and condemnation. Suicide is the act of killing yourself, most often as a result of depression or other mental illness. (1). Suicide is defined by World Health Organization (WHO, 2004 ) as "the act of intentionally killing oneself" (as cited in (2). Globally, there is one completed suicide in every 40 seconds while five percent of people in the world try to kill themselves at least once during their lifetime. Annually, 800,000 people commit suicide. Around $79 \%$ suicides are from low or middle income countries. (3).

The highest documented suicide rates can be found in Eastern European countries like Lithuania and Russia, while they are lowest in Latin America, however, China has the one of the highest female suicide rates in the world (3). In Asian countries, rural areas also seem to be a 
risk factor for suicide. In China, the rate of suicide in rural areas is three times higher than that of urban areas. In India, the rate is also three times higher than the overall national rate. A study in Bangladesh showed that the sex ratio for mental disorders was 2:1 and that for suicide was 3:1 (4)). However, review showed that statistics of last fifty years depict the problem of suicide altering its trend. Suicide rates were higher in Western-Europe and then this trend moved to Eastern-Europe and now it is moving to Asia. India and china have the leading global suicide trend, while South Korea's suicide rate is on continuous rise since last decade. (5)

Approximately $60 \%$ of world's suicide is accounted in Asian countries, including China, Sri Lanka, Bangladesh, India, Afghanistan and Pakistan but some countries like Pakistan and Afghanistan do not have national reports on suicide rates (6). The numbers of attempted and/or completed suicide may be underestimated in Pakistan. Basic epidemiological data, for example, on national rates are not known (7). Limited evidences showed that suicides have increased over the past few years (7) (8).

Pakistan is a Muslim country, Islam forbids taking one's life and suicide is viewed as a dishonorable act from religious and sociocultural perspectives (9) (7) (8) (10) (11) argued that in almost 17 Islamic countries suicidal deaths are categorized as "Other Violent Death (OVD)" as these deaths are culturally unacceptable but with this categorization the lower suicidal rates are reported in these countries but the exact rates are unknown. However, (12), discussed the underlying mechanism of suicide and its relationship with Islam. The exact underlying factors and the main attributes of sociocultural determinants remain uncertain and unstipulated in attempted suicide or completed suicide by people particularly women.

The official statistics of suicides are not known hitherto in Pakistan. According to un-official reports, suicidal attempts (completed suicides) are increasing in urban and rural areas of Pakistan such as Sindh, Punjab, and Gilgit-Baltistan (13) (14) (15) (16) (17) (18). (13), claimed their study as first of its kind which discussed risk factors using a matched-pair case-control method for suicides in Pakistan. Studies of suicide from Pakistan are few and mostly descriptive case series in nature (19) (14) (20). However, the prevalence of suicide and selfharming behavior in particular remains difficult to measure due to the often uncertain nature of these acts.

Much has been written about suicide motivation and the nature of the act by philosophers and theologians through the ages. It has especially fascinated social scientists for two reasons: due to its universality, and its very nature and definition; suicide constitutes a form of deviant behavior. Both of these reasons make suicide an important and major object of social inquiry. This has led to an exploding literature on suicide and it could have been written today also shows how important this topic is. The objectives of this paper are to explore the concept of suicide, the existing consensus and figures of suicide in Pakistan (and Asian countries), the main determinants of suicide, the identified risk factors and predictors associated with suicides, the modes of suicide discussed in the existing literature of Pakistan, and to analyze the literature gap and limitations of the suicidal evidences.

\section{Concept of Suicide;}

Suicide is considered a sin from Islamic perspective. Pakistan being an Islamic country constituting 97\% Muslims not only considered suicide as sin but subsequently it became criminal offense (Pakistan Penal Code 309), in legal definition. (21). However, it is argued that, the legal implications for suicide attempter raises ethical issues, because suicidal behaviors mostly precipitated by prevailing socio-economic conditions, which are directly related to government policies. (22) 


\section{Existing statistics of suicide in Pakistan}

Pakistan does not provide suicide statistics to WHO but Non-governmental organizations like Aurat Foundation, have some information on suicide deaths in Pakistan which is derived from published studies. It is observed that police and law enforcement agencies are normally reluctant to intervene in suicidal cases because these cases are usually resulted in domestic dispute (23), so police do not report the true frequency of suicides in Pakistan. It is reported by (24), that during the three months period police did not report even a single of suicide in any police station but Pakistani newspapers reported 91 suicides in Pakistan during this period. Thus, this discrepancy shows that there is a very strong need for an upgraded system of registration of suicides in Pakistan (23) (10) (24), particularly excluding any influential factors. In newspapers during the period of 2010-2017, highest number of the student suicide cases were reported from Punjab (52.9\%), while from Sindh (23.6\%) and from Khyber Pakhtunkhwa (8.9\%) (25).

Research evidences indicate that suicide has been reported from major cities of Pakistan including Karachi, Larkana, Lahore, Multan, Bahawalpur, Faisalabad, Rawalpindi and Peshawar. Unofficial rates vary from a low of $0.43 / 100,000$ per year (average for 1991-2000) in Peshawar to a high of 2.86/100,000 for Rawalpindi (in 2006), with other cities falling in between: Karachi, 2.1/100,000 (1995-2001); Lahore, 1.08/100,000 (1993-95); Faisalabad, 1.12/100,000 (1998-2001) and Larkana, 2.6/100,000 (2003-2004).Gender- specific rates show that for men, highest rates are 5.2/100,000 in Rawalpindi, while for women the highest rates are 1.7/100,000 in Larkana. The highest age- and gender-specific rates for men and women are in the age group 20-40 years: 7.03/100,000 and 3.81/100,000 in Larkana, respectively. (8) (20) (26) (27) (28)

(14), studied the patterns of suicide in autopsies conducted at Faisalabad from 1998 to 2001 and investigated the incidence of suicide, during January 1, 1998 and December 31, 2001. Results of this study suggested suicide rate was $1.12 / 100,000$, with male preponderance while peak incidence was in 20-29 years in males and 10-19 years in femalesThe Dawn newspaper reported 5800 committed suicide during first nine months of the year 2006 due to poverty, unemployment and depression. This consensus was revealed in a report on human rights issued by the Lawyers Committee for Human Rights, Pakistan same year. In 2007, the Human Rights Commission of Pakistan (HRCP) recorded 2,040 suicide cases, including 692 by women. Financial hardship, or domestic problems, which the commission said were often triggered by issues relating to finances. (29), reported that there were 1,153 attempted suicides across Pakistan and 2,131 suicides in 2011 with five or six teenagers attempting suicide every day in Karachi. Of these, 60 per cent are teenage girls and families are reluctant to register the case as attempted suicide (as cited by (16). (25), analyzed the reported student suicide incidents in renowned newspaper of Pakistan during the period of eight years (2010-2017). Total 67 cases were retrieved from news reports, among them 52 were male students (76.5\%) and 16 were female (23.5\%). Similarly, a study reviewed 100 cases during 2013-2014 from three health centers of Pakistan. Results of this study showed that highest suicidal ratio (53.6\%) was found in unmarried individual, which included males $(40.2 \%)$ and female $(60.8 \%)$. While among married $41.2 \%$ males and $33.9 \%$ female cases, in divorced it was $6.3 \%$ and in widowed $3.9 \%$, collectively. This study also showed that more than $1 / 3^{\text {rd }}$ of total retrieved cases were student suicide attempters. (30)

In recent years, the attempted and completed suicide in female is increasing in Ghizer (10), and Hunza (18), areas of Gilgit-Baltistan (GB; formerly known as Northern Areas of Pakistan) which is a rural and remote mountainous region of Pakistan. Studies showed a high rate of 14.9 among women in Ghizer district during the period 2000-2004 (31). Khan et al. (10), calculated 
suicide rates of women during years 2000 to 2004 in the Ghizer by taking average mean population for women for 5 years as 65,783, the annual crude suicide rates for women as $14.89 / 100,000 /$ year was calculated. He and his colleagues reported 49 women committed suicide of age-specific rates for 15-24 years. Khan et al. (10), insisted that these figures are considerably higher than suicide rates in other parts of Pakistan and may be related to high psychiatric morbidity in Pakistani women. According to media reports, from 2005 to 2011, about 340 women committed suicides (18). Due to increase in such cases, the Government of GB has established a Women Police Department in 2011, to account the female issues like suicide and domestic violence. Along with this the Women Police Department is trying to find out the causes behind suicide and to introduce the preventive strategy in order to prevent or reduce the suicide among women in the district.

\section{Determinants of suicide}

Suicide is a multi-dimensional disorder, which results from a complex interaction of biological, genetic, psychological and environmental factors and mainstream suicides were committed due to poverty and economic hardships. Khan (23), emphasized on the religious and existing legal factors which were considered as current state of suicide and attempted suicide in Pakistan by highlighting the main findings of the few studies carried out over the last 50 years in his study (7). But in majority cases of completed suicide, it is quite difficult to report or collect data accurately in the presence of the existing social, legal and religious factors (7). There has been growing concern regarding the relative importance of social determinants in suicide such as poverty and gender disadvantage related to oppressive attitudes towards women in many countries as being major contributors to the risk for attempted and completed suicide (7) (32).

Domestic issues, marital status and gender difference as determining factors in suicide: Critelli (33), discussed marital dissatisfaction or domestic violence that could lead towards the intentions of divorce, or attempted/completed suicide. Similarly, most frequently cited stressful events of young rural women in India were unhappy marriage, financial problems, and beaten by spouses (34). However, females living in the domestic and gender violence environment were more determine to attempt or commit suicide. Further, females living in male dominant societies such as Pakistan, Afghanistan, Bangladesh, and India also have more chances to attempt or commit suicide (35). Generally it is reported that interpersonal relationship problems, domestic disputes and financial problems are the underlying causes of suicides in Pakistan (19) (14) (36), however, Khan M (13) identified depression as principal diagnosis in attempted suicide. Further, marriage also appears to be a significant source of stress (especially for women), leading to high psychological morbidity and suicidal behavior (37).

Some studies reported "a high prevalence of common mental disorders in Pakistani women $29-66 \%$ for women compared to $10-33 \%$ for men" (38) and some studies reported that women living in mountainous villages of Chitral and Ghizer (GB) were suffering from anxiety and depression (39) (40). Married women are also more likely to attempt suicide (41). (23), revealed that the most frequent factors forcing women to commit suicide were conflicts with husband and in-laws. Similarly, marital discord, mental and physical abuse from husband, helplessness, low self-esteem, financial constraints imposed by the husband, and in-law problems are salient psychosocial stressors for women (42) (43). If woman gets divorce, she has to face innumerable problems such as rejection from society, financial constraints, and emotional problems of single-parent children. A study by Zafar Ahmed and his colleagues (44) also revealed that domestic problem is the highest (54\%) prevalent cause of suicide in Chitral 
and Khaber Pakhtoonkhaw, second to it is lack of confidance and tolerance (32\%) and mental illness (14\%).

While presenting the suicide data (i.e rates, reasons, mode, risks etc.) almost every study taken into account the gender differences, however, mixed results were seen as in many studies male suicide rate is shown higher, while in various other female are said to have higher suicide rate. Many studies also differentiate on the basis of marital status where more married females have committed suicide then single, while opposite trend is revealed for male gender. (45) (46) (47) (48) (49) (50)

Contrary to these studies, a research on 50 attempted suicide cases in South Punjab revealed that more unmarried people attempted suicide then married and among them men outnumber women in suicide attempt. However, describing about the causes of suicide, personal problem is common among females and failure in love in males. (48).

A study by Bibi Rahnuma and others (51) revealed that out of 251 respondents, $32.6 \%$ viewed financial problem as the main cause, while $8.7 \%$ believed domestic issues as the major contributors towards suicide problem. Furthermore, $27 \%$ stated that marital conflicts result in suicide and $30.2 \%$ viewed societal interference in individual's success and failure as the main cause of suicide in Gilgit-Baltistan region.

\section{Economic status, occupation and education as determining factors in suicide;}

It is also suggested that in developing countries the social and economic stressors are more significant risk factors or stressors for suicide as compared to mental illness (52) (53) (54). It is an established fact that unemployment has a positive correlation with suicide, suicidal ideation and self-harming behavior. While reviewing the literature, unemployment and financial constrains are also describe as the cause of suicide in various studies, where suicide victims are described as low income earner or belonged to low socio-economic class of society (27) (55) (56) (57) (58) (59). In a case-control study of 100 suicide cases in Karachi stated that $39 \%$ suicide victims are unemployed (13).Correlation was also drawn between level of education of victim and suicide and attempted suicide in various studies, and it is reported that suicide is more prevalent in individuals having no or low education. A significant figure, that is $21 \%$ suicide victims were uneducated out of 100 suicide cases, is reported in a case control study (13).

Among student suicide, as analyzed by Muneeba Shakil (25), based on newspaper reports, showed that $(23.6 \%)$ of suicide were because of failure in exam, while scolding of parents concerning to academic performance cause $11.8 \%$ suicide. Moreover, failure in love was the reason of suicide in $8.8 \%$ cases, family issues in $5.9 \%$, harsh attitude of teachers and administration in $5.9 \%$, dissatisfaction with life in $4.4 \%$, pressure of studies in $2.9 \%$, ragging by seniors in $2.9 \%$ and poverty in one suicide case.

Khokher and Khan (60), studied about the prevalence of suicidal behavior and suicidal ideation among Pakistani college students. Result showed that rate of suicidal ideation among female was $33 \%$, while $29.2 \%$ in male. Students residing hotel were reported to have the higher rate of suicidal ideation. Researcher also suggested that to understand the contributing factors of suicide it is imperative to collect more information about suicidal behavior, including feelings in school going children, to address the problem of suicide in students at various level.

Results of the study indicated that $13.9 \%$ of all the students had once considered in their life time to commit suicide, and $4.8 \%$ of the total 331 students have attempted suicide in their life. 
Study stated that suicidal ideation in medical students in Pakistan is the consequence of the over-burden of study, educational issue, high expectations of family, and high degree of stress. As medical profession is a highly acclaimed and students of unprivileged families when got admission in medical college, their parents' high expectations become a source of stress (61). Suicidal ideation among medical students in Pakistan is never been studied except a solitary study published in 2005 (60). Suicide is treated as taboo, hence, not explicitly discussed. Such behaviors are disgraceful, and lead to alienation and stigmatization of vulnerable and enhance the suicidal ideation, and then suicide rate (61).

\section{Risk factors of Suicide:}

Those characteristics which increases the likelihood of an individual to contemplate, attempt or commit suicide are said to be the risk factors. Suicide can have diverse risk factors which can better understand by collecting information related to social, economic and health factors, which can give provide the better picture of contributing risk factors for the attempted or completed suicide (62).

Bibi Rahnuma (51), argued that rapid social change bringing a visible shift in mountainous culture and society, which transformed the society from pastoral to agricultural subsistence and then to government and non-government jobs, leading towards merchant society and then to capitalist society. During this transformation social values are moving from collectivism to individualism, leaving the individuals alone in their problems with diminishing social support. Thus leading to alienation and frustration which are the major risk factors of suicide.

Khan and his colleagues identified major risk factors and predictors associated with suicides in Karachi, Pakistan and these predictors are psychiatric disorders (especially depression), while being married, unemployment, negative and stressful life events could be the risk factors of suicide (13). Three studies investigated deliberate self-harm and identified precipitating and risk factors in hospitalized patients in Karachi Pakistan in the duration of January 1997 and August 2003 (63), 2008-2009 (64), and March 2011 and February 2012 (65). Findings of these studies revealed mental illnesses, low socio-economic status and loneliness as the risk factors while precipitating factors included family conflict, marital problems, chronic illnesses, unemployment and comorbid psychiatric disorders among deliberate self-harm patients.

Muhammad Osama (61), in a study on suicidal ideation in medical students, stated that risk of developing suicidal ideation is highest in students who indulged in substance abuse. Tendency of developing is also greater in students who are neglected by parents, and have psychiatric disorders.

In Pakistan particularly unemployed male individuals are at risk of suicidal and self-harm behavior, as unemployment showed strong correlation with suicide (66). Thus unemployment, and generally poor economic conditions of society with rising poverty are of great policy concern, as these are the macro level risk factor in suicide (67). Moreover, it is also stated in a review study (49), that low educational attainment has significant correlation with suicide. It is thought that low educational attainment profoundly affects the individual by developing poor stress coping abilities, lack of capability to compete for jobs and to acquire high social standing (68).

Further, Sher, S. \& Dinar, H. (2) studied the casual factors of suicide in Ghizer such as social (e.g. academic pressure, divorce, financial constraints, and relational problems), cultural (e.g. limited personal freedom, demand for male child and lack of decision making power) and psychological (mental illness and depression) factors. Some studies asserted that educational 
pressure, over expectations of parents and hopelessness are among the main factors of suicide in Ghizer (18) (2) and Hunza (18) due to increase in educational facilities, exposure to modern technology, and increase in overall literacy rate in GB. (18), insisted that the existing social structure in GB and conflict between tradition and modernity has taken into consideration while addressing the suicidal rates in Ghizer and Hunza. Only one report stated high level of domestic violence in women in GB (69).

The rising fees in academic institutes, elevating level of competition among students due to demanding environment of educational institutions, and insufficient social support system consequence into elevated level of stress among students. Thus fear of failure, parents'/teacher's admonishment and peer pressure are major risk factors for suicides among students in Pakistan. Another factor is socio-economic and cultural difference, as students in academic institutions belonged to diverse cultural and socio-economic backgrounds. Thus, competition among students is not only academic but socio-economic and cultural competition also exists. (25)

Initial studies showed that Kalash, an indigenous tribe in Chitral, Pakistan, did not support the concept of death because the people believed that the life given to them is a gift of god so they have no right to end it. No suicidal cases had been reported or documented before 1988 (70) (71) but in 1996 suicide become the relatively frequent in Chitral, usually the attempted or completed suicide is connected with the experience of failed love, and it becomes a great cause of anxiety in attempted suicide individuals (72) or sometimes suffer from heart attack (73). Gradually increasing suicide in Chitral also raising the questions as such deaths were actually cases of honor killing. Marsden (73) emphasized that 'it is common in these death cases for the dead woman's parents to file official charges against the husband's family, accusing them of murdering the girl on grounds of suspected infidelity, or, more frequently, on the suspicion that the man desired to marry another woman but was forbidden to do so by his existing wife'. On the other hand, it is also observed that the forced arranged marriages between Chitrali women and Punjabi men are also precipitating factors of suicides in these women (73). However, another factor which leads towards suicides was to express the desire to choose a marriage partner, which is mostly considered as disobedience in Pakistani society (37) or in some cases young couples, who marry by family opposition and face un resolvable clash either live apart by severing ties or choose suicide either together or alone (2).

\section{Modes of suicide.}

It is not surprising that suicide is one of the leading causes of death in young women in Asia (7) (74) (75) due to easily access to toxic methods such as pesticides but limited to medical services. (13), stressed that the low number of cases with previous history of self-harm, and family history of suicide and self-harm were similar to those from China (76), India (77), and Sri Lanka (74), that also show high fatality in first-time attempters, although not in others such as Taiwan (78). In Pakistan, the most common method of suicide was hanging (14), followed by poisoning (13). Majority patients, usually females, used drugs (64) such as benzodiazepines (63) or organophosphate pesticides (13) for self-poisoning.

A scoping review of literature from Pakistan also confirm that that poisoning is found to be the second most commonly used method to commit suicides in Pakistan. Moreover, as Pakistan is an agricultural country, thus pesticides can be easily available in rural setting, which are also shown to be the highly used in self-poisoning (49).

The descriptive analysis of 100 retrieved cases from three health centers of Pakistan, found that the most common method used was drug overdose (40\%) while wrist cutting was among 
$20 \%$ cases. Other modes, including jumping from height, hanging, chemical poisoning, and suicide burn were $10 \%$ each. However, it was also revealed that by hanging $100 \%$ cases died, while $77.7 \%$ by jumping, $40 \%$ by wrist cutting, and only $1.5 \%$ died by drug overdose. (30). A study based on news reports, showed that hanging was the mostly used method among students (33.8\%), while gun shooting was (27.9\%), poisoning was $(13.2 \%)$, jumping from height was (5.9\%), self-immolation was (4.4\%) and wrist cutting was (1.5\%) (25)

However, women living in mountainous areas especially of Gilgit, Ghizer, \& Hunza usually jumped in river/lake for suicide (10). Some studies also reported firearms as mode of suicide (19) (7). While in some suicidal cases, completed suicide victims used to burn themselves as a certain method for suicide (13).

\section{Literature gap and limitations}

Studies that were discussed in this article also have limitations. The accurate official statistics of suicidal data is not documented or reported, so usually epidemiological data was based on the partial accessibility to the suicidal victims or families who reported to police or electronic media. Majority studies lack the prospective cohort design in a community setting within the country. The past few years, however, brought some noteworthy advancement of the research into the epidemiology, etiology, and treatment of suicidal behavior in the patients (hospitalized). Hence, the research based on epidemiology, etiology, and treatment of suicidal behavior among all ages, social class, or ethnic groups are ignored. One of the major barriers during suicidal reports was observed that is also a potential risk factor associated with suicide that is family or police's misclassification of some suicides (13), and these misclassification neglected the true causes of attempted or completed suicide. It is also observed that in some studies contradictory number of completed suicides were given such as in the case of (2) so in this paper author has given authentic figures from Khan studies (7) (8) (10) (18).

Another major gap found in the reviewed studies focus of various studies is on exploring rates of suicide on regional basis, also more focus is given to statistical analysis of demographic variables of completed or attempted suicide, but detailed, exploratory, and in-depth study to find out the main determinant and risk factors of suicide in socio-cultural context is not carried out. Moreover, the recommendations given in various studies are more of general nature rather including the special context of communities under studied. Pakistani society has unique regional and cultural diversity, which needs such suicide prevention strategies, which will be devised by keeping in view the specified socio-cultural context of target community. As evident from the literature in urban settings most common mode of suicide is hanging (14), while in rural areas it is poisoning (49), however in mountainous region drowning in water bodies and gun shot is more prevalent (44).

Lastly, the existing literature on suicide in Pakistan is devoid of establishing the concept of suicide, also the social meanings of suicide are not been identified, discussed or explored in any study.

\section{CONCLUSION}

Suicide is a growing public health issue in Pakistan. Despite of religious-cultural sanctions and legal prohibitions, suicide problem is on rise, which gather the attention of various researcher, thus producing a body of literature. However, there is no national statistics on suicide, and the growing literature on suicide are the efforts by researchers to account and identify the suicide statistics, its determinants, modes and risk factors. This review is also an attempt to summarize the available literature and to identify the gaps in available literature on suicide. This draws attention to the extent of suicide problem, recounting the statistics, determinant, 
modes and risk factor of both suicide and suicide attempts in Pakistan by drawing on all available data. This review found that Pakistan's socio-cultural diversity also depicted in varying rates of suicide across the various regions, also differences in determinants of suicide, and even diversity in use of method to commit suicide. Thus, it is suggested to prevent suicide, various socio-cultural parameters at community level should be taken into consideration. Moreover, existing literature has more focus on quantitative aspect of suicide, however, further anthropological and psychological studies are suggested at the community level to understand the exact underlying determinants of suicide.

\section{References}

APA. American Psychological Association. https://www.apa.org/index. [Online] 09 23, 2019. https://www.apa.org/topics/suicide/.

Ethnography of suicide: A tale of female suicides in district Ghizer, Gilgit-Baltistan. Sher, S. \& Dinar, H.. 6, 2015, The Explorer Islamabad: Journal of Social Sciences,, Vol. 1, pp. 207-210.

WHO. World Health Organization. https://www.who.int/. [Online] 09 23, 2019. https://www.who.int/newsroom/fact-sheets/detail/suicide.

Gender Inequality in Mental Health: A Review from the South Asian Context. Tabassum R. 2, 2017, Bangladesh Journal of Medical Science, Vol. 16, pp. 203-206.

Suicide in the World. Värnik, Peeter. 2012, Int. J. Environ. Res. Public Health, Vol. 9, pp. 760-771.

Suicide in Asia: Opportunities and Challenges. Ying-Yeh Chen, Kevin Chien-Chang Wu, Saman Yousuf, Paul S. F. Yip. 1, 2012, Epidemiologic Reviews, Vol. 34, pp. 129-144.

Beyond rates: the tragedy of suicide in Pakistan. . Khan, M. M.,\& Prince, M.,. 2003, Trop Doct., Vol. 33, pp. 67-9. Suicides in the developing world: case study from Pakistan. . Khan MM, Ali Hyder A. 2006, Suicide Life Threat Behav., Vol. 81, pp. 26-76.

Issues in forensic psychiatry in Islamic jurisprudence. Chaleby, K. S. 1996, Bulletin of the American Academy of Psychiatry Law,, Vol. 24, pp. 117-124.

Female Suicide Rates in Ghizer, Pakistan, . Khan, M. M., Ahmed, A., \& Khan, S. R. 2009, Suicide and LifeThreatening Behavior, Vol. 39, pp. 227-230.

An analysis of suicide and undetermined ('other violent deaths') deaths in 17 predominantly 'Islamic countries' with the United Kingdom. Pritchard, C., \& Amanullah, S. 2007, Psychological Medicine, Vol. 37, pp. 421-430.

Islam and suicide: a short personal communication. Rezaeian, M. 1, 2009, Omega (Westport), Vol. 58, pp. 77-85.

Case-control study of suicide in Karachi, Pakistan. Khan MM, Mahmud S, Karim MS, Zaman M, Prince M. 2008, Br J Psychiatry., Vol. 139, pp. 402-5.

Epidemiology of suicide in Faisalabad. Saeed, A., Bashir, M. Z., Khan, D., Iqbal, J., Raja, K. S.,\& Rehman, A. 2002, Journal of Ayub Medical Collage Abbottabad, Vol. 14, pp. 34-7.

An audit of suicide in Karachi from 1995-2001. Ahmed, Z, Ahmed, A, \&Mubeen, S. M. 2003, Ann Abbasi Shaheed Hospital,, Vol. 8, pp. 424-8.

The alarming rise of teenage suicides in Pakistan. Ebrahim, Z. T. 2012, Published in Dawn News on Jun 08, 2012.

Female Suicide Rates in Ghizer, Pakistan,. Khan, M. M., Ahmed, A., \& Khan, S. R. 2, 2009, Suicide and Life-

Threatening Behavior, Vol. 39, pp. 227-230.

Self, society and suicide in Gilgit. Dad, A. A.,. 2014, International the News.

Changing pattern of suicide and parasuicide in Karachi. Ahmed, S. H., \&Zuberi, H. 1981, Journal of Pakistan Medical Association, Vol. 31, pp. 76-8.

An audit of suicide in Karachi from 1995-2001. Ahmed Z, Ahmed A, Mubeen SM. 2003, Ann Abbasi Shaheed Hosp., Vol. 8, pp. 424-8.

The Pattern of Suicide in Pakistan. Khan, Murad. 1, s.l. : Hogrefe \& Huber Publishers, 2000, Crisis, Vol. 21.

The one truly serious philosophical problem': Ethical aspects of suicide. M. M. Khan \& A. I. Mian. 3, 2010, International Review of Psychiatry, Vol. 22, pp. 288-293. 
Suicide and parasuicide in Pakistan. Khan, M M..(1998). 1998, Journal of Crises International and Suicide Prevention, Vol. 19, pp. 148-151.

Newspaper reports as a source of injury data in developing countries. Ghaffar, A., Hyder, A. A., \& Bishai, D. 2001, Health Policy Planing, Vol. 16, pp. 322-325.

A Qualitative Analysis of Suicides Committed by the Students in Pakistan. Muneeba Shakil. 1, 2019, Pakistan Journal of Medical Research, Vol. 58, pp. 35-40.

Suicidal deaths: assessment in Peshawar. . MZ., Bashir. 2003, The Professional. .

Management of acute organophosphorus insecticide poisoning: an experience at a university hospital. Shaikh JM,

Siddiqui FG, Soomro AG. 2008, JLUMHS, Vol. 7, pp. 96-101.

EPIDEMIOLOGY OF SUICIDE IN FAISALABAD. Ahmad Saeed, M. Zahid Bashir, Delawar Khan, Javed Iqbal, Khurram Sohail Raja, Anayatur Rehman. 4, 2002, Journal of Ayud Medical College Abbotabad-pakistan, Vol. 14.

HRCP. Human Rights Commission of Pakistan. [Online] 2011. http://hrcp-web.org/hrcpweb/.

An Alarming Situation of Suicide Patterns and Methods Involved in Pakistan. Adnan Liaqat, Aisha Barlas, Talal Barlas, Muhammad Adnan, Ishtiaq Anwar. 3, 2017, American Journal of Psychiatry and Neuroscience. , Vol. 5, pp. 37-39.

\section{Health Net TPO Report. 2013.}

Suicide in farmersi n India. Sundar, M.,. 1999, .British Journal of Psychiatry, Vol. 175, pp. 585-6.

Between Law and Custom: Women, Family Law and Marriage in Pakistan. Critelli, F. M.,. 5, 2012, Journal of Comparative Family Studies, Vol. 43, pp. 673-693.

Poisoning deaths in married women. Kumar, V.,. 2004, Journal of Clinical Forensic Medicine, Vol. 11, pp. 2-5.

Religion and Suicide Prevention in Asia. Hendin.H. 2008, World Health Organization.

Causes and outcome of suicidal cases presented to a medical ward. Shoaib, S., Nadeem, M. A., \& Khan, M. Z. U. 2005, Ann KE Med College, Vol. 11, pp. 30-2.

Marital satisfaction in Pakistan: A pilot investigation, . Farah Qadir, Padmal de Silva, Martin Prince \& Murad Khan. 2, 2005, Sexual and Relationship Therapy, Vol. 20, pp. 195-209.

Risk factors, prevalence, and treatment of anxiety and depressive disorders in Pakistan. Mirza, I., \& Jenkins, R.,. 2004, Systematic review British Medical Journal, Vol. 328, pp. 794-797.

Stress and psychiatric disorder in the Hindu Kush: A community survey of mountain villages in Chitral, Pakistan. Mumford, D. B., Nazir, M., Jilani, F. U., \& Baig, I. Y. 1996, British Journal of Psychiatry, Vol. 168, pp. 299-307. Center-based prevalence of anxiety and depression in women of the northern areas of Pakistan. Dodani, $\mathbf{S} ., \mathbf{\&}$ Zuberi, R. W. 2000, Journal of the Pakistan Medical Association, Vol. 50, pp. 138-140.

Suicide and parasuicide in Pakistan: Time for a change? Khan, M. M., \& Reza, H. 1998, Journal of the Pakistan Medical Association, Vol. 48, pp. 292-293.

Domestic violence and health of Pakistani women. Fikree, F. F., \& Bhatti, L. I. 1999, International Journal of Gynaecology and Obstetrics, Vol. 65, pp. 195-201.

The minds of mothers: maternal mental health in an urban squatter settlement of Karachi. Rabbani, F., \& Raja, F. F. 2000, Journal of the Pakistan Medical Association, Vol. 50, pp. 306-312.

TRENDS AND PATTERNS OF SUICIDE IN PEOPLE OF CHITRAL, KHYBER PAKHTUNKHWA, PAKISTAN. Zafar Ahmed, Qadar Nisa, Abdul Wahab Yousufzai, Shariq Khoja. 2, 2016, KMUJ , Vol. 8.

Suicidal symptoms in depressed Pakistani patients. Javed MA. 1996, J Pak Med Assoc., Vol. 46, pp. 69-70.

Methods of deliberate self-harm in Pakistan. Khan MM, Reza H. 1996., The Psychiatrist Bulletin., Vol. 20, pp. 367-8. Self-inflicted or homicidal cut throat: a retrospective study. Malik S, Rana P, Rasheed A, Farrukh R, Aziz K. 1999, Ann King Edward Med Uni., Vol. 5, p. 325.

The Causes and Prevention of Suicide Attempts in Southern Punjab Pakistan: The Normative Role of Media. Ghulam Shabir, Shafaq Manzoor, Ghulam Safdar. 1, 2015, Journal of Business and Social Review in Emerging Economies, Vol. 1.

Suicide and deliberate self-harm in Pakistan: a scoping review. Shekhani et al. 44, 2018, BMC Psychiatry, Vol. 18, pp. 13-15. 
Causes and outcome of suicidal cases presented to a medical ward. Shoaib S, Nadeem MA, Khan ZU. 11(1), 2016, Ann King Ed Medic Uni., Vol. 7.

Causes of Suicide in Gilgit-Baltistan Region. Bibi Rahnuma, Ji Fangtong, Masood Ali Khan, Kamran Saddique, Intikhab Ahmad. 8, 2017, EUROPEAN ACADEMIC RESEARCH, Vol. 5, pp. 4041-4051.

Suicide and social change in China. Phillips, M., Liu, H., \&Zhang, Y. 1999, Cult Med Psychiatry, Vol. 23, pp. 25-50. Suicide in developing countries (2): risk factors. Vijayakumar, L., John, S., Pirkis, J.,et al. 2005, Crisis, Vol. 26, pp. 112-9.

World mental health: problems and priorities in low-income countries. Desjarlis, R., Eisenberg, L., Good, B., ef al, eds. 1995, New York: Oxford University Press, pp. 68-86.

Relationship between suicidal ideation, social support and coping skills in female prisoners of a jail in Pakistan. Rasheed S, Sawal M, Taj R, Najam N. 2005, J Pak Psych Soc (JPPS)., Vol. 2.

Deliberate self-harm. Haider S, Haider I. 2001, J Pak Med Sci., Vol. 17, pp. 1-7.

Suicidal Behavior (Parasuicide). Haider S, Haider I. 2002, Med Channel., Vol. 8, pp. 9-12.

Epidemiology of attempted suicides in emergency of Mayo Hospital in 2004. Asif A, Yusuf F, Haider K, Gul H, Usman S, Akbar S, et al. 2016, Ann King Ed Med Uni., Vol. 11.

Short communication-deliberate self-poisoning: experience at a medical unit. Khurram M, Mahmood N. 2008, J Pak Med Assoc., Vol. 58, p. 455.

Suicidal ideation in Pakistani college students. Khokher S, Khan MM. 2005, Crisis, Vol. 26, pp. 125-7.

Suicidal ideation among medical students of Pakistan: A cross-sectional study. Muhammad Osama, Muhammad Yousuf-Ul Islam, Syed Ather Hussain, Syed Muhammad Zia Masroor, Muhammad Usman Burney, Muhammad Atif Masood , Ritesh G. Menezes, Razaur Rehman. 2014, Journal of Forensic and Legal Medicine, Vol. 27, pp. 65-68.

Why women attempt suicide: the role of mental illness and social disadvantage in a community cohort study in India. Maselko, J., \& Patel, V. 2008, Journal of Epidemiology and Community Health, Vol. 62, pp. 817-822.

Deliberate self-harm: characteristics of patients presenting to a tertiary care hospital in Karachi, Pakistan. Zakiullah, N., Saleem, S., Sadiq, S., Sani, N., Shahpurwala, M., Shamim, A., Yousuf, A., Khan, M. M., \& Nayani P. 1, 2008, Crisis, Vol. 29, pp. 32-7.

Deliberate self-harm in the emergency department: experience from Karachi, Pakistan. Shahid, M., Khan, M. M., Saleem, K. M., Jamal, Y., Badshah, A., \& Rehmani, R. 2, 2009, Crisis, Vol. 30, pp. 85-9.

Risk factors for deliberate self-harm in patients presenting to the emergency departments of Karachi. Shahid, M., Iqbal, R., Khan, M. M., Khan, M. Z., Shamsi, U. S., \& Nakeer, R. 1, 2015, Journal of the College of Physicians \& Surgeons Pakistan, Vol. 25, pp. 50-5.

Pattern of deliberate self-harm in young people in Karachi, Pakistan. Syed EU, Khan MM. 2008, Crisis, Vol. 29, pp. 159-63.

Deliberate self-poisoning (unemployment and debt). Haider S, Haider I. 2002, J Pak Med Sci., Vol. 18, pp. 122-5. Pakistani couples: different productive and reproductive realities. . Sathar ZA, Kazi S, Mahmood A. 2000, The Pakistan Development Review. , pp. 891-912.

AGHE. Violence against women in northern areas of Pakistan. . Association of Global Humanists and Ethics (AGHE) \& Ghizer Rural Advancement Foundation (GRAF). Ghizer District, Northern Areas : s.n., 2006. In Seminar report: White ribbon day 2006.

Beyond the North-West frontier: Travels in the Karakorum's. Maureen, L. 1988, Spark ford: Oxford Illustrated. An Ethnographic Analysis of Death and Burial Customs in Kalash Community of Chitral District of Khyber Pakhtunkhwa Pakistan. Sheikh, I., Naz, A., Hazirullah, Khan, Q., Khan, W., \& Khan, N. 10, 2014, Middle-East Journal of Scientific Research, Vol. 21, pp. 1937-19.

Love and marriage in a Sri Lankan Muslim community: toward a reevaluation of Dravidian marriage practices. De Munck, V. 1996, American Ethnologist, Vol. 23, pp. 698-716.

Love and Elopement in Northern Pakistan. Marsden, M.,. 1, 2007, The Journal of the Royal Anthropological Institute,, Vol. 13, pp. 91-108. 
Deliberate self harm in Sri Lanka: an overlooked tragedy in the developing world. Eddleston, M., Sheriff, M. H., Hawton, K. 1998, BMJ, Vol. 317, pp. 133-5.

Suicide in young people in rural southern India. Aaron, R., Joseph, A.,AbrahamS, et. al. 2004, Lancet, Vol. 363, pp. 1117-8.

Risk factors for suicide in China: a national case-control psychological autopsy study. Phillips, M. R., Yang, G., Zhang, Y., Wang, L., Ji, H., Zhou, M. 2002, Lancet, Vol. 360, pp. 1728-36.

Are risk factors for suicide universal? A case-control study in India. Vijayakumar, L.,\& Rajkumar, S. 1999, Acta Psychiatr Scand, Vol. 99, pp. 407-11.

Psychosocial and psychiatric risk factors for suicide: case-control psychological autopsy study. . Cheng, A. T. A., Chen, T. H. H., Chen, C. C., \& Jenkins, R. 2000, British Journal of Psychiatry, Vol. 177, pp. 360-5.

Suicide in ethnic and cultural minorities - a research on literature. Giupponi, G., Conca, A., Schmidt, E., Hinterhuber, H., Pompili, M., \& Pycha, R. 2, 2011, Neuropsychiatrie: Klinik, Diagnostik, Therapie and Rehabilitation, Vol. 25, pp. 93-102.

Suicidal behaviors among youth in Pakistan and prevention. . N., Pachani. 2014, J Pioneer Medi Sci . 